Article

\title{
Interactions of Solitary Wave with a Submerged Step: Experiments and Simulations
}

\author{
Wei-Ting Chao ${ }^{1}$, Shin-Jye Liang ${ }^{2, *}$, Chih-Chieh Young ${ }^{1,2, *}$ and Chao-Lung Ting ${ }^{3}$ \\ 1 Center of Excellence for Ocean Engineering, National Taiwan Ocean University, Keelung 20224, Taiwan; \\ away19850624@gmail.com \\ 2 Department of Marine Environmental Informatics, National Taiwan Ocean University, Keelung 20224, Taiwan \\ 3 Department of Engineering Science and Ocean Engineering, National Taiwan University, \\ Taipei 10617, Taiwan; chaoting@ntu.edu.tw \\ * Correspondence: sjliang@ntou.edu.tw (S.-J.L.); youngjay@ntou.edu.tw (C.-C.Y.); \\ Tel.: +886-(2)-2462-2192 (ext. 6317) (S.-J.L.); +886-(2)-2462-2192 (ext. 6318) (C.-C.Y.)
}

Citation: Chao, W.-T.; Liang, S.-J.; Young, C.-C.; Ting, C.-L. Interactions of Solitary Wave with a Submerged Step: Experiments and Simulations. Water 2021, 13, 1302. https:// doi.org/10.3390/w13091302

Academic Editor: Luca Martinelli

Received: 22 March 2021

Accepted: 3 May 2021

Published: 6 May 2021

Publisher's Note: MDPI stays neutral with regard to jurisdictional claims in published maps and institutional affiliations.

Copyright: (c) 2021 by the authors. Licensee MDPI, Basel, Switzerland. This article is an open access article distributed under the terms and conditions of the Creative Commons Attribution (CC BY) license (https:// creativecommons.org/licenses/by/ $4.0 /)$.

\begin{abstract}
A series of experiments exploring the propagation of a solitary wave over a submerged step were performed using a flow-field visualization measurement system, an image-connection technique as well as model simulations. The experimental data were used to validate a one-layer finite-element non-hydrostatic model and a multi-layer finite-difference non-hydrostatic $\sigma$ model for various submerged step configurations and wave conditions-combinations of step height ratios $d / h$, width ratios $B / h$ and solitary wave height ratios $H / h$, where $d$ denotes the step height, $B$ the step width, $H$ the solitary wave height, and $h$ the still water depth. The main differences between the numerical results and the experimental data are highlighted. The effect of the height and width of the submerged step as well as the wave height of the solitary wave are quantified in terms of reflection $(R)$, transmission $(T)$, and energy dissipation $(D)$. Through a series of numerical experiments, an optimal combination of the height ratio $d / h$, width ratio $B / h$, and solitary wave height ratio $H / h$ for breakwater design for coastal protection is suggested.
\end{abstract}

Keywords: dissipation; non-hydrostatic; reflection; solitary wave; submerged step; transmission

\section{Introduction}

Tsunamis, which are typically generated by underwater earthquakes, are one of the most destructive natural disasters. These powerful, large, and long waves have caused devastating tragedies in many coastal regions. For example, the 2004 Indian Ocean tsunami led to at least 230,000 dead or missing people, representing the deadliest recorded tsunami in human history. In 2011, a strong earthquake struck eastern Japan and produced a tsunami with a height exceeding $40 \mathrm{~m}$, leading to at least 20,000 casualties and losses in excess of 360 billion dollars [1]. To protect residential communities in coastal areas [2-4], artificial structures with an appropriate design can be used to mitigate the impacts of such events. In this context, understanding the influences of submerged obstacles on tsunamis is essential and important for effective engineering.

To represent the kinematic characteristics of tsunamis, solitary waves (solitons) have been frequently utilized since the 1970s. Solitary waves derived from the KdV equation can be used as the proper inputs of tsunamis for physical and mathematical models [5-8]. It is particularly noteworthy that the NOAA Technical Memorandum implies that the solitary wave is still the preferred model of tsunamis [9], while some studies have been seeking a link between solitary waves and geophysical tsunamis [10].

As solitary waves propagate through a shallow water region over an irregular bed (e.g., a mild slope or underwater obstacle), several interesting phenomena occur. Part of the wave energy is reflected (i.e., as a reflected wave), while the remainder passes over the obstacle and continues to propagate forward (i.e., as a transmitted wave) [11-16]; 
additionally, some of the energy is lost due to the friction on the wave-bottom or the corner (i.e., as a dissipation) [17-22]. Moreover, nonlinearity becomes more important for solitary wave propagation as the ratio of wave height and relative depth increases [23]. Thus, the coastal structures along the shoreline need to be properly designed (in terms of geometry) to provide the required protection standard with an economic balance [24,25].

Over the past decades, in addition to analytical theories, laboratory experiments and numerical simulations have been widely applied to investigate solitary waves passing over a submerged step (e.g., [5,18,26,27]). Regarding analytical theories, Kanoglu and Synolakis [28] provide a general method to evaluate the evolution of solitary waves under linearly varying ocean topographies or constant-depth segments. A weakly nonlineardispersive theory (e.g., the Korteweg-de Vries (KdV) equation) has also been applied to study the solitary transformation over a step and the process of soliton fission if the submerged obstacle length is larger than the solitary wave length $[29,30]$. For conventional experiments, researchers have utilized wave gauges to record the deformation as waves cross a sudden change of the channel geometry $[5,17,31]$. However, owing to the limitations of measuring instruments, a complete spatial wave profile cannot be easily obtained. In the last three decades, non-intrusive particle image velocimetry (PIV) systems (with single-section images) have been developed. Furthermore, effective image-connection techniques [32,33] have been proposed to capture the entire variation of the free surface as the water waves propagate onto an uneven topography. Therefore, full spatial information can be utilized to study not only the reflection, transmission, and dissipation of waves, but also the generation of vortices and their variations on the lee and weather sides and run-up processes [34-40].

Moreover, the availability of sufficient experimental data provides numerical models for rigorous/thorough validation. Numerical simulations of complex flow fields offer an alternative way to study the interactions between solitary waves and structures. Besides, numerical modeling reduces the workload involved in physical experiments such as wave-structure interaction during the process of vortex generation [41,42] and wave breaking [43-45]. For example, Lin [18] examined this effect with a complete range of step width-height ratios; e.g., from a thin plate to a shelf and from a submerged obstacle to an emerged object.

The purpose of this study is two-fold: first, a series of experiments with a flow-field visualization measurement system and the image-connection technique were conducted to investigate the interactions of a propagating solitary wave with a submerged step. Experimental conditions included various heights and widths of the step as well as incident wave heights. Second, these experimental data were used as the validation benchmark for two non-hydrostatic models: a one-layer depth-averaged model [46] (hereafter referred to as the FE model) and multi-layer $\sigma$ model [47] (hereafter referred to as the FD model). Both FE and FD models were employed to examine the effects of submerged step configurations and solitary wave conditions on the reflection $(R)$, transmission $(T)$, and energy dissipation $(D)$ through a series of numerical experiments. The two models were first verified with a solitary wave propagating in a constant-depth channel where an analytical solution was available. The combined effect of the height and width of the submerged step and wave height of solitary wave is then discussed.

In the following, Section 2 describes the experimental setup and the treatment of image processing. Section 3 briefly introduces the two non-hydrostatic models. Section 4 presents the data analysis processes. Section 5 presents the model verification. The results and discussion are given in Section 6. Finally, the conclusions are presented in Section 7.

\section{Experimental Setups and Image Processing}

A series of experiments were conducted in a $20 \mathrm{~m}(L) \times 0.8 \mathrm{~m}(H)$ wave flume at the Fundamental Fluid Laboratory in the Department of Engineering Science and Ocean Engineering at National Taiwan University, with a working depth $h$ of $0.1 \mathrm{~m}$ (as shown in Figure 1a). A piston-type wave maker with a feedback displacement sensor equipped at the 
front end of the tank was utilized to generate solitary waves using Rayleigh's method [48]. A 1:10 slope was constructed at the other end of the tank to reduce the reflected waves returning into the measurement area. A submerged obstacle was placed $7 \mathrm{~m}$ from the wave maker with the coordinate origin located at the still water level above, where the positive $\mathrm{X}$-axis was directed toward the rear of the tank and the vertical $\mathrm{Z}$-axis was positive and upward. Eight laboratory experiments (see Table 1) with two submerged step height-still water depth ratios ( $d / h$ of 0.5 and 0.7$)$, four submerged step width-height ratios $(B / h$ of $10-30$, and 50), and two solitary wave height ratios $(H / h$ of 0.09 and 0.133$)$ were conducted.

(a)

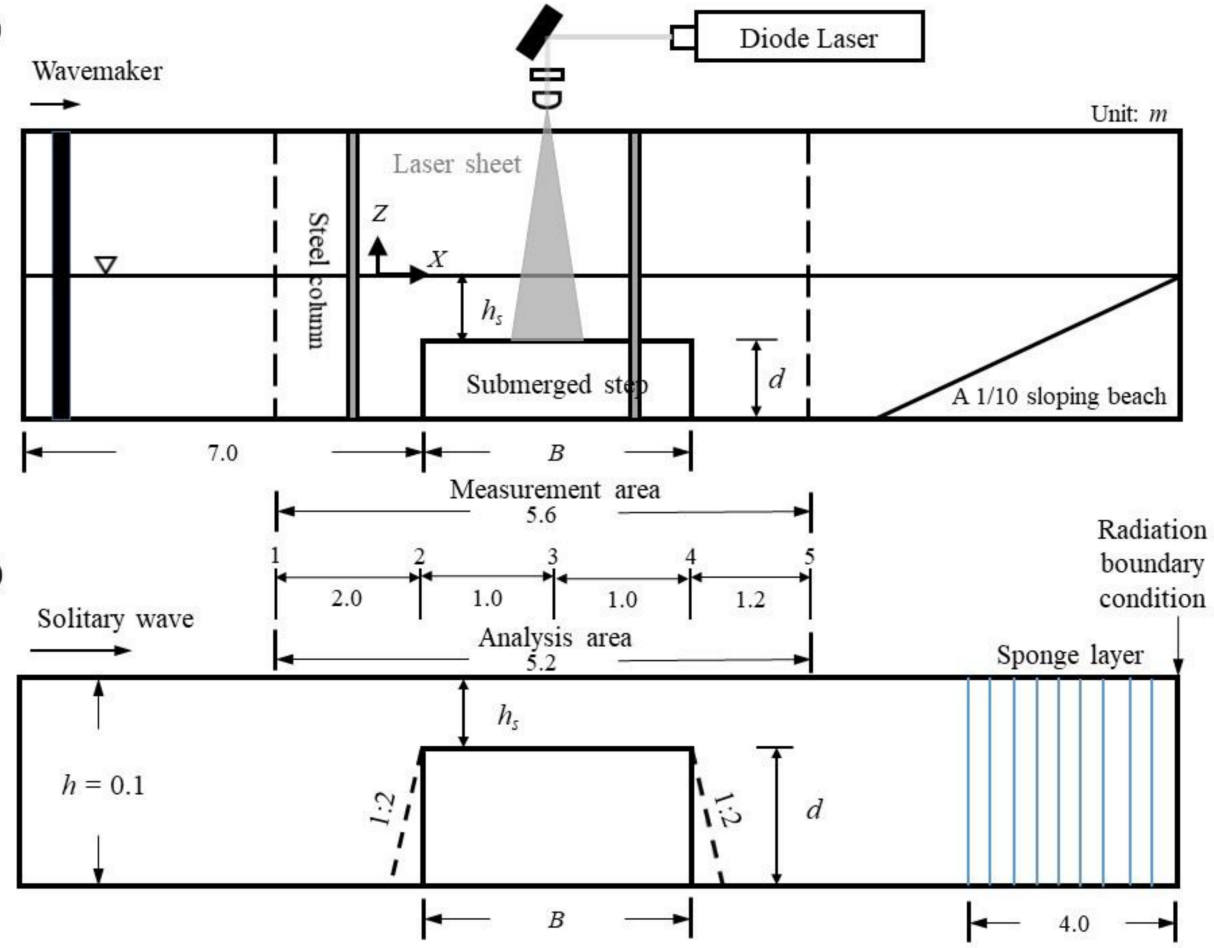

Figure 1. Illustration of setup of (a) experiments and (b) model simulations.

Table 1. Summary of configuration of submerged steps and conditions of solitary wave of experiments and model simulations (e.g., working depth $h$ of $0.1 \mathrm{~m}$ ).

\begin{tabular}{cccc}
\hline & \multicolumn{2}{c}{ Step Geometry } & \\
\cline { 2 - 3 } Case No. & $\boldsymbol{B}(\mathbf{m})$ & $\boldsymbol{d}(\mathbf{m})$ & \\
\hline Case 01 & & 0.05 & 0.009 \\
Case 02 & 10 & 0.05 & 0.0133 \\
Case 03 & 10 & 0.07 & 0.009 \\
Case 04 & 10 & 0.05 & 0.009 \\
Case 05 & 20 & 0.07 & 0.009 \\
Case 06 & 20 & 0.07 & 0.0133 \\
Case 07 & 20 & 0.05 & 0.009 \\
Case 08 & 30 & 0.05 & 0.009 \\
\hline
\end{tabular}

* indicates condition of laboratory experiments for model verification.

A non-intrusive measurement system was used to record free-surface elevations. This system comprised a $3 \mathrm{~W}$ green-colored diode laser with a $532 \mathrm{~nm}$ wavelength, a set of optical lenses (i.e., a spherical lens with a $500 \mathrm{~mm}$ focal length, a cylindrical lens with a $12.7 \mathrm{~mm}$ focal length, and several reflectors), and a high-speed video camera. The pointsource laser was directed into the measurement area through optical lenses, forming a light sheet at the center of the water tank $(0.15 \mathrm{~m}$ from both of the lateral sides). With the tracer dye Rhodamine-B illuminated in the water, waveforms could be recorded by a high-speed camera. 
The high-speed video camera had a maximum frame rate of 250 frames/s at full resolution $(512 \times 480$ pixels). Two cylindrical lenses with focal lengths of $100 \mathrm{~mm}$ and $200 \mathrm{~mm}$ were placed in front of the camera to increase the resolution along the vertical axis (Z). The horizontal and vertical resolutions of the images were 12.2 and 44.0 pixels $/ \mathrm{cm}$, respectively, with a magnification of 3.6. The video area began from $x=5.0 \mathrm{~m}$ in front of the submerged obstacle (i.e., offshore) and covered a length of $5.2 \mathrm{~m}$ (see Figure 1a). Note that the full length of $5.2 \mathrm{~m}$ could not be captured instantaneously due to the design capacity of the video camera and the limited space of the laboratory.

As suggested in past studies [32,33], the region of examination $(R O E)$ was further divided into 26 sections. The waveform in each section was recorded by moving the video camera along the sidewall of the tank with the same trigger time. In addition, the total recording time and frame rate were set to $15.0 \mathrm{~s}$ and $125 \mathrm{frames} / \mathrm{s}$, respectively. Overall, the difference between the measured and averaged waveforms was less than 2 pixels $( \pm 0.045 \mathrm{~cm})$ along the $\mathrm{Z}$ axis, demonstrating the excellent capability of the measurement system.

Figure 2 depicts a typical snapshot (Case 06) of the waveform in the ROE and the complete free surface variations in the spatial-temporal 2D domain. The white and gray pixels in Figure 2a represent water areas, and the black pixels above the red line represent air. Through an edge-detection technique, the free-surface at the interface of the air and water can be distinguished (see the red curve). Note that the dark gray bars indicate the steel columns of the wave flume. The unknown waveform is interpolated from the information on both sides of the column in the blocked area. The simple three-point moving average method is utilized to smooth the small surface fluctuations from the edge-detection process.

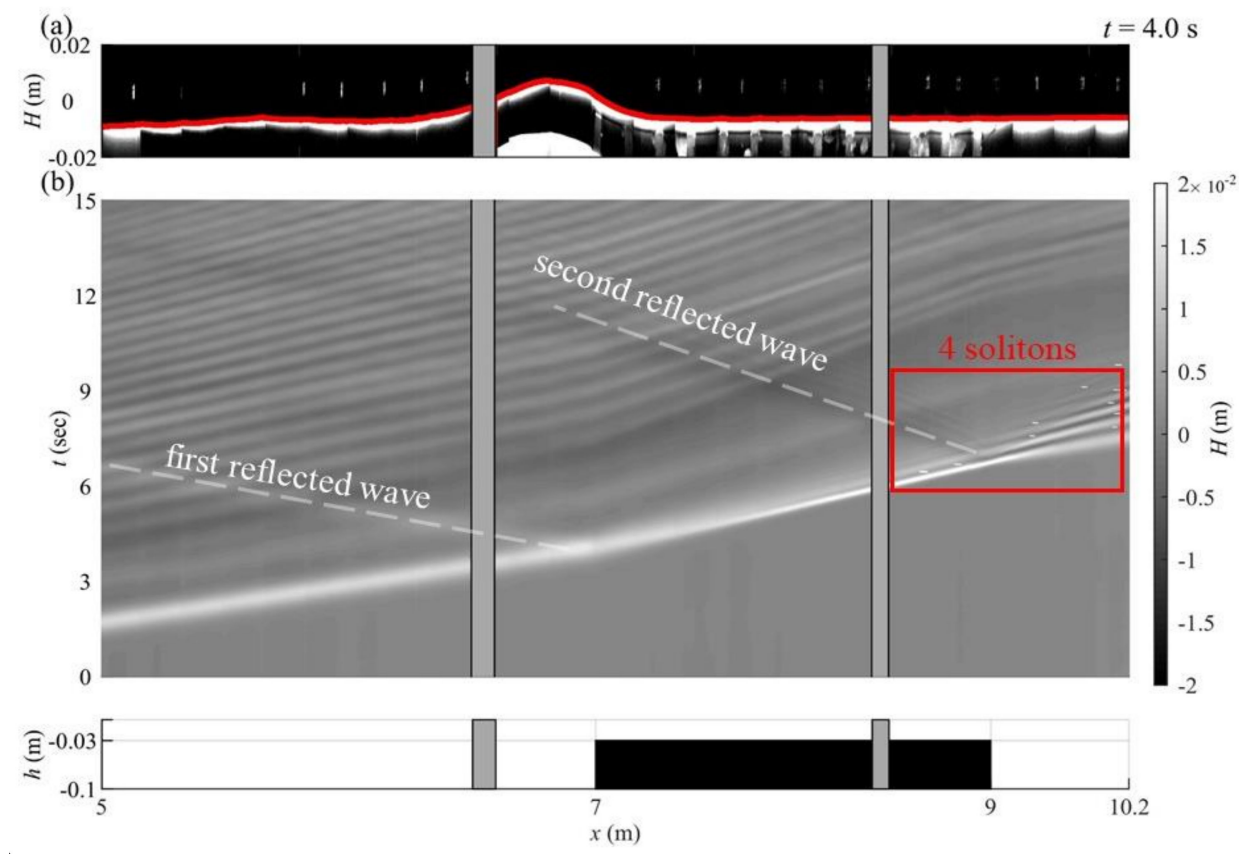

Figure 2. (a) Snapshot of the free surface and (b) 2D spatial-temporal results of the waveforms of experimental results of Case 06 after post-processing.

Further, Figure $2 \mathrm{~b}$ shows the full spatial-temporal information of waveforms by arranging the free-surface spatial profiles detected at different time instances. The complicated patterns imply the existence of the incident and reflected waves and fission solitons. The detailed physical process and model simulations of solitary wave propagation over the submerged step are described in Sections 5 and 6. 


\section{Numerical Models}

Two non-hydrostatic models based on the Navier-Stokes equations/Euler equations with non-hydrostatic pressure were developed and used in this study: one is the multi-layer finite-difference (FD) $\sigma$ model $[47,49]$, and the other is the one-layer finite-element (FE) model [46]. Both FD and FE models are developed based on the hydrostatic predecessors.

\subsection{Multi-Layer Finite-Difference Non-Hydrostatic Shallow-Water $\sigma$ Model}

The multi-layer finite-difference non-hydrostatic $\sigma$ model (NHM) developed in $[47,49]$ was used to simulate the propagation of solitary waves in this study. With the aid of advanced computer capacity, this type of model provides a general simulation tool for ocean/coastal research [50-53]; e.g., periodic wave propagation over a rapidly varying topography [52]. The efficient $\sigma$ model solves the unsteady, incompressible Navier-Stokes equation with the coordinate mapped from the Cartesian domain $x^{*}-z^{*}-t^{*}$ (e.g., the symbol star represents under Cartesian domain) into the $x$ - $\sigma-t$ terrain following one (e.g., see $[47,50,54])$. Through the boundary-fitted transformation, the free surface (i.e., $\sigma=0$ for $z^{*}=\eta\left(x^{*}, t^{*}\right)$ ) and the irregular bottom (i.e., $\sigma=-1$ for $z^{*}=-h\left(x^{*}, t^{*}\right)$ ) can be exactly represented to ensure computational accuracy. Based on the commonly-used staggered grid system $[47,51,55]$, the pressure is arranged at the center of the cell.

The total pressure consists of the hydrostatic component caused by the free-surface elevation and the non-hydrostatic component attributed to the vertical acceleration [56]. A special treatment to integrate the vertical momentum equation from the center of the top-layer cell to the free surface was proposed to obtain the top-layer pressure boundary condition $[47,49]$. Thus, only a small number of vertical layers is required to accurately simulate highly nonlinear dispersive waves; e.g., 2-5 vertical layers for a dimensionless water depth $k h$ of 3-15 [51]. For boundary conditions, an irregular unmovable bottom is applied. Through the integration of the continuity equation over the water depth with associated kinematic conditions, the conservative form of free-surface equation is utilized. At the inflow boundary, either the free-surface elevation or horizontal velocities of incident waves (according to the analytical solutions or laboratory conditions) are specified [55] with a ramp-function to avoid undesired disturbance from the impulse motion [57,58]. For the outflow boundary, both a Sommerfeld radiation boundary condition and a sponge layer technique are employed to minimize wave reflection [55].

\subsection{One-Layer Finite-Element Non-Hydrostatic Shallow-Water Model}

A 2D depth-averaged finite-element non-hydrostatic shallow water model has been developed and applied to simulate the ocean circulation the Dongsha waters [46]. The model is based on the existing hydrostatic shallow-water model $[59,60]$. In the nonhydrostatic shallow-water model, the pressure is decomposed into hydrostatic and nonhydrostatic components, as Casulli [61,62] and the Keller-box scheme [63] did for the vertical gradient approximation of the non-hydrostatic pressure in the formulation. The depth-integrated shallow water equations including non-hydrostatic pressure terms were solved with the linear distributions assumed in the vertical direction for both the nonhydrostatic pressure and the vertical velocity. The depth-integrated non-hydrostatic flow model is solved semi-implicitly: the provisional flow velocity is first implicitly solved using the hydrostatic shallow-water equations; then, the non-hydrostatic pressure, which is implicitly obtained by ensuring a divergence-free velocity field, is used to correct the provisional velocity; and finally, the depth-integrated continuity equation is explicitly solved for the free-surface elevation to satisfy global mass conservation [57,64-67].

The 2D one-layer non-hydrostatic shallow water model is based on the least-squares finite-element formation. The resulting system of equations is symmetric and positivedefinite. Therefore, a pre-conditioned conjugate-gradient method is used to solve the resulting system of equations and found to be very efficient $[59,60]$. 


\section{Data Processing}

Wave signal analysis plays an important role in defining the wave reflection, transmission and energy dissipation caused by a submerged structure. Note that the widely used frequency analysis methods (e.g., the fast Fourier transform or wavelet transform) are inappropriate for evaluating a solitary wave because its wavelength (or period) is theoretically infinite; a soliton is composed of infinite frequency components. Based on the spatialtemporal measurement results, the reflected and transmitted waves were successfully separated according to the following approaches.

\subsection{Reflected Waves}

In the wave flume, the solitary wave generated by the wavemaker was typically followed by oscillatory tails due to a sudden shut-down of the wavemaker paddle. Generally, the solitary wave propagates much faster to the step than the oscillatory tails. As a consequence, on the weather side of the step, the partially reflected wave (see the time series at position 2) and oscillation tails did not meet each other even briefly. Furthermore, the free-surface elevation time series at position 1 (see Figure 1) with a time window that contained neither reflected waves nor tails was carefully selected for the incident signal. Thus, based on the characteristic of linear superposition, the crest from the deviation between position 1 and 2 can be defined as a reflected wave $\left(H_{R}\right)$ and it can be easily extracted from complicated wave signals., giving the reflection coefficient $R$ :

$$
R=\frac{H_{R}}{H_{I}},
$$

where $H_{I}$ and $H_{R}$ are the wave heights of incident and reflected waves, respectively.

As the solitary wave propagates onto the submerged step (see the illustration of Case 06 in Figure 2), a number of solitons were generated due to the increased nonlinearity in the shallow water region. On top of the submerged step, several small crests (light gray color in Figure $2 b$ ) formed between the soliton (white color in Figure $2 b$ ) and oscillatory tails, shown in the red box of Figure 2b. When the solitons re-entered the deep-water region, the change in depth caused another reflection that could not be easily identified from the traditional measurements provided by a single wave gauge in the earlier works. Such a difficult problem is overcome by analyzing the recorded imagery with a similar procedure. An obvious reflection crest was observed on the lee side beginning at $t=6 \mathrm{~s}$ (Figure $2 \mathrm{~b}$ ); thus, the second reflected waves were calculated by the time series data between positions 3 and 4 . Besides, four fissions of soliton-like waves were generated (illustrated in the red box) in the lee side of the submerged step due to the release of the free energy and generation of high numbers of harmonics.

\subsection{Transmitted Waves}

After partial reflection, the fission-induced soliton-like waves continued to propagate as transmitted waves passing over the step to the lee side. To avoid the disturbance from the boundary-reflected wave from the end of the flume, the surface elevation time series between $6 \mathrm{~s}$ and $12 \mathrm{~s}$ at position 5 were used to represent the general transmitted wave of Case 06. It is clearly observed that there were four fission solitons with wave heights smaller than that of the incident wave (see red box of Figure 2b). However, it is not easy to identify the transmitted wave height during the fission process. Therefore, we utilized the suggestion of Lin [18], who reported that the integration of energy flux is sensible under such conditions. Each wave crest before the oscillatory tails arrived (e.g., before $t=12 \mathrm{~s}$ ) at position 5 were defined as the transmitted wave height $\left(H_{T}\right)$. The transmission coefficient can be expressed based on the energy conservation:

$$
T=\frac{\sqrt{C_{g s}}}{\sqrt{C_{g d}}} \frac{H_{T}}{H_{I}}
$$


where $C_{g d}=\sqrt{g h}$ and $C_{g s}=\sqrt{g(h-d)}$ are the group velocities in the deep-water region and on the step, respectively. The dissipation coefficient is computed with Equation (3), where the largest wave height of reflected waves and solitons are used in the reflection and transmission coefficient defined in Equations (1) and (2). In addition, the dissipation coefficient can be represented as

$$
D=\sqrt{1-R^{2}-T^{2}}
$$

\section{Model Verification: Propagating Solitary Wave in a Constant Depth Channel}

A solitary wave propagating in a one-dimensional channel with a constant depth was used for model verification. The analytical expressions for a solitary wave are

$$
\begin{gathered}
\eta(x, t)=H \sec ^{2}\left[\sqrt{\frac{3}{4} \frac{H}{h}}\left(x-x_{0}-c t\right)\right] \\
U(x, t)=\frac{\eta c}{\eta+h} \\
W(x, t)=-(\eta+h) \frac{\partial U}{\partial x} \\
q(x, t)=-\rho(\eta+h) \frac{\partial W}{\partial t}
\end{gathered}
$$

where $H$ is the wave height, $h$ is the constant water depth, $c=\sqrt{g(H+h)}$ is the wave propagation speed, $\eta$ is the approximation of free surface, $U(W)$ is the horizontal (vertical) velocity on the free surface based on the shallow water approximation, and $q$ is the dynamic pressure at the bottom.

For this case, the channel had a constant water depth $h$ of $0.1 \mathrm{~m}$ and length $L$ of $20 \mathrm{~m}$. A solitary wave with an $H$ of $0.0138 \mathrm{~m}$ was considered. For model simulations, spatial and temporal increments were $\Delta x=0.01 \mathrm{~m}$ and $\Delta t=0.005 \mathrm{~s}$, respectively. In contrast to $\mathrm{FE}$ ( $\Delta x=\Delta y=0.01 \mathrm{~m}$; i.e., 2000 uniform quadrilateral elements), the FD utilizes five vertical layers to allow an accurate wave dispersion property in model computations $(\Delta x=0.01 \mathrm{~m}$; i.e., 2000 uniform grids and five vertical layers).

Approximations of $\eta, U$ and $W$ in Equations (4)-(6) with $x_{0}=5.0 \mathrm{~m}$ and $t=0.0 \mathrm{~s}$ were used as initial conditions for both FD and FE models. Figure 3 shows the comparison of the horizontal velocity $U$ (Figure 3a), vertical velocity $W$ (Figure $3 b$ ), and dynamic pressure $q$ (Figure 3c) at $t=0,5$, and $10 \mathrm{~s}$ of the analytical solution, the one-layer FE model, and the multi-layer FD model. It can be seen that the simulation of both numerical models agrees well with the analytical solutions. However, note that the FD model presents some small fluctuations in the dynamic pressure in the form of dispersive tails. Based on our previous study [51], the FD model with five vertical layers provided excellent dispersive properties for free-surface wave modeling up to a dimensionless water depth $k h$ of 15 . A possible reason for such unexpected fluctuations might be attributed to the approximated horizontal velocities at incident boundaries. The low-order solution of horizontal velocity (i.e., shallow water approximation) is non-dispersive and not fully consistent with the wave profile from KdV equation. Further, the solitary wave evolution obtained from experiments and simulations was compared for various time instances in Figure 4. Note that wave profiles in an enlarged area (i.e., $x=7.0 \mathrm{~m}$ to $9.25 \mathrm{~m}$ within $\mathrm{ROE}$ ) are presented here for better comparison. Overall, the experimental data and model predictions are in excellent agreement. 

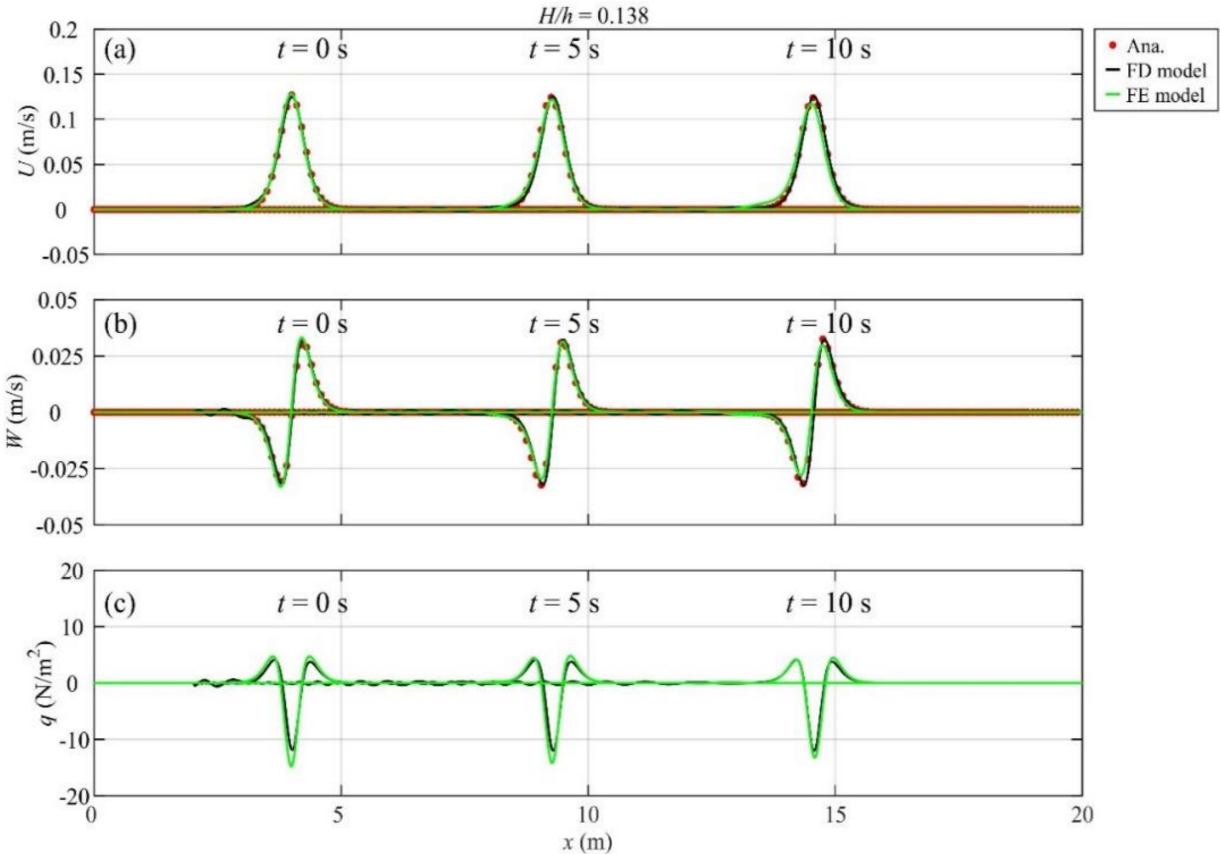

Figure 3. Comparison of approximations with computed results of a propagating solitary wave in a flat channel at $t=5$ and $10 \mathrm{~s}$ : (a) horizontal velocity, (b) vertical velocity, and (c) dynamic pressure, respectively (circles denote analytical solution; black lines denote FD model results; green lines denote FE model results).

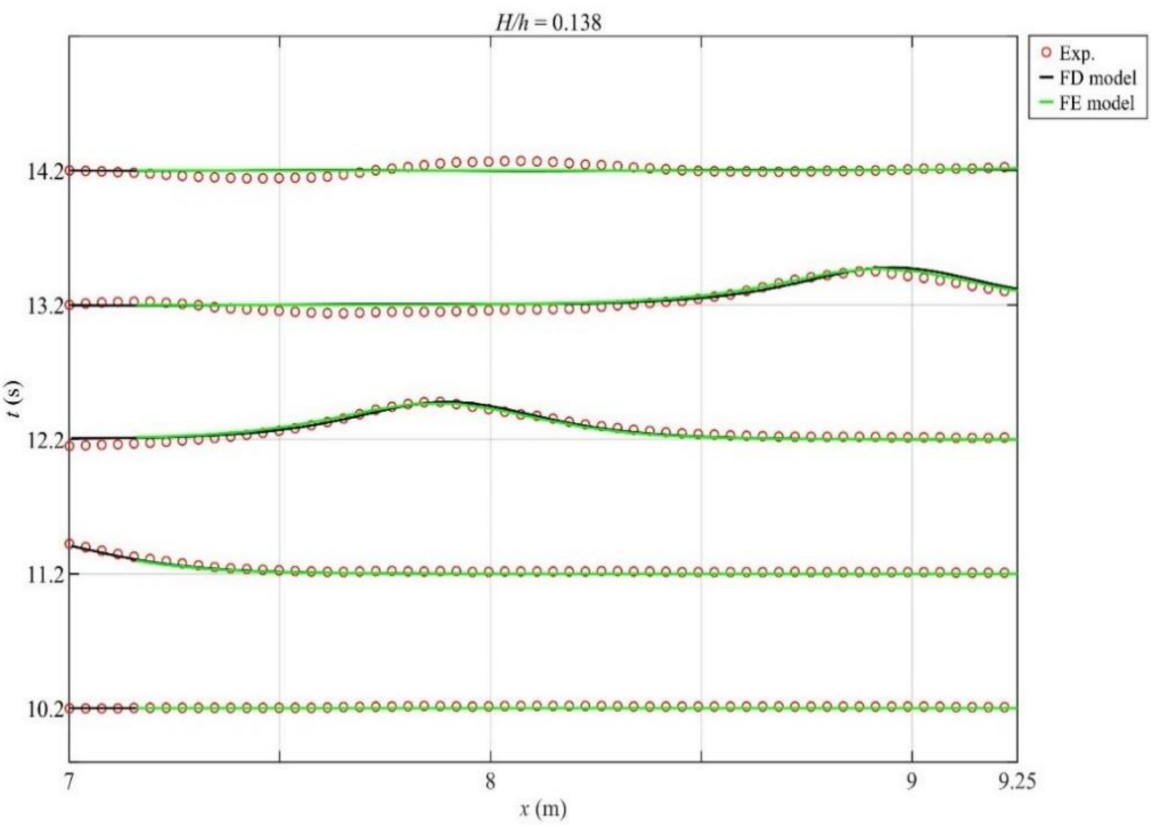

Figure 4. Comparison of free-surface of experiment with model result for a propagating solitary wave in a flat channel at various time instances (circles denote experimental data; black lines denote FD model results; green lines denote FE model results).

\section{Results and Discussion}

The main objective of this study was to investigate the effect of step height and width as well as solitary wave height on solitary wave transformation. The effects were quantified in terms of the coefficient of reflection $(R)$, transmission $(T)$, and dissipation $(D)$ for both experimental and numerical results. The computational grids and time integration increases of the two numerical models used were the same as those in the previous simulations. 
Note that a similar bottom configuration was adopted in numerical simulations except for virtual slopes (see Figure 1b). In fact, the experimental results indicate that the evolution of waves (amplitude or energy) presents a smoother transitional variation rather than an abrupt change as waves propagate onto the submerged step. Therefore, the bottom smoothing strategy-i.e., a steep virtual slope (1:2)—was proposed to approximate a true vertical step, especially for a sigma-coordinate model [32,52]. By bottom smoothing, reasonable modeling results can be obtained for both transmitted and reflected waves. More discussions can be found in our previous paper [52]. For consistency, this bottom smoothing strategy has also been used in our one-layer FE model.

\subsection{Effect of Submerged Step Height}

A propagating solitary wave with a wave height $H$ of $0.009 \mathrm{~m}$ over a step with a step width $B$ of $1.0 \mathrm{~m}$ and heights $h$ of 0.05 and $0.07 \mathrm{~m}$ in a channel with a still water depth $h$ of $0.1 \mathrm{~m}$ were conducted experimentally and numerically to study the effect of the submerged step height on the free-surface evolution and wave transformation. The computational grids and time integration increases of the two numerical models used were the same as those in the previous simulations.

Figure 5 shows the comparison of the experimental measurements with the two model simulation results. The solitary wave approached the submerged step at around $t=4 \mathrm{~s}$, passed over the step, and transmitted again to the deep-water region at $t>6 \mathrm{~s}$. Subsequently, fission solitons were generated. The wave evolution and transformation process was more pronounced for the tall step (i.e., $d / h$ of 0.7 in Figure $5 b$ ) than for the short step (i.e., $d / h$ of 0.5 in Figure 5a). It is also noticeable that the experimental data show some fluctuations at $t=8 \mathrm{~s}$ due to the sudden shut-down of the wavemaker paddle. Overall, the numerical results agree with the experiment data well in general. As the solitary wave is transmitted over the higher step, however, one can observe some discrepancies in the simulation results (see wave profiles at $t=6$ and $8 \mathrm{~s}$ in Figure $5 \mathrm{~b}$ ), which may result from different dispersive properties between the two models. In other words, the FE model with one vertical layer could not capture those high-frequency oscillations.

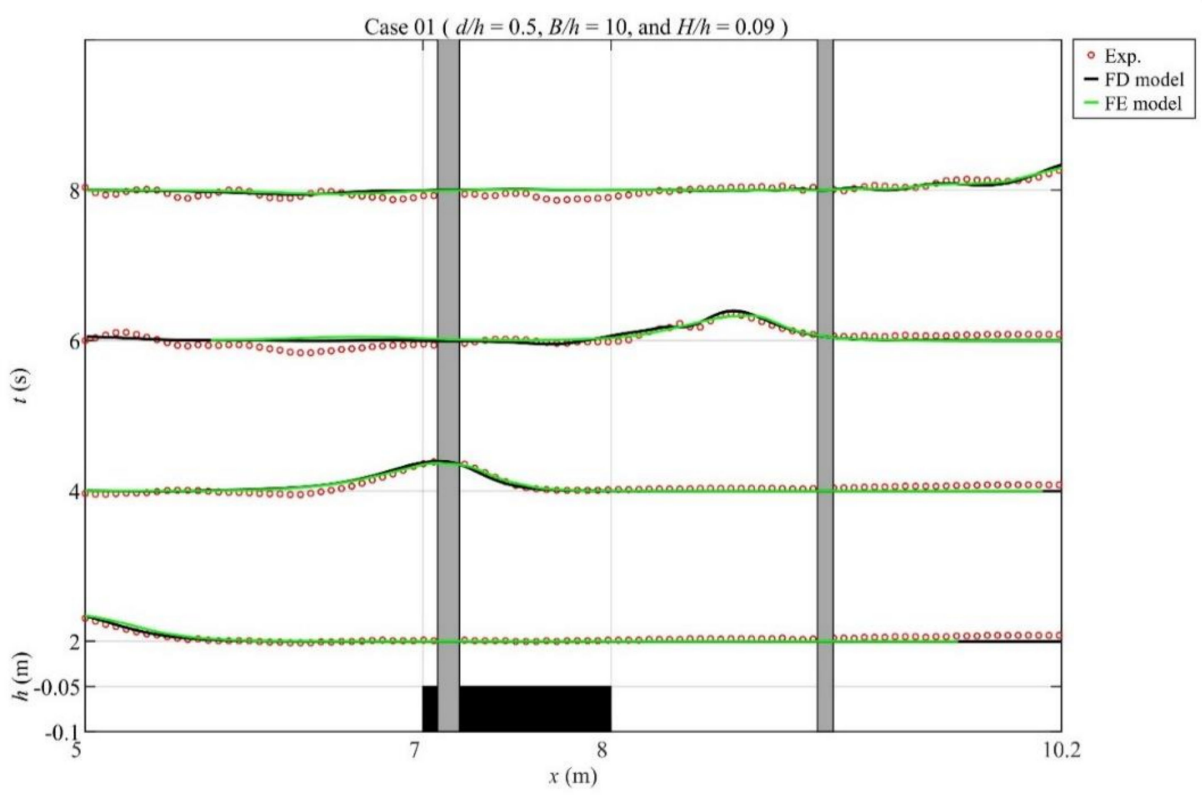

(a)

Figure 5. Cont. 


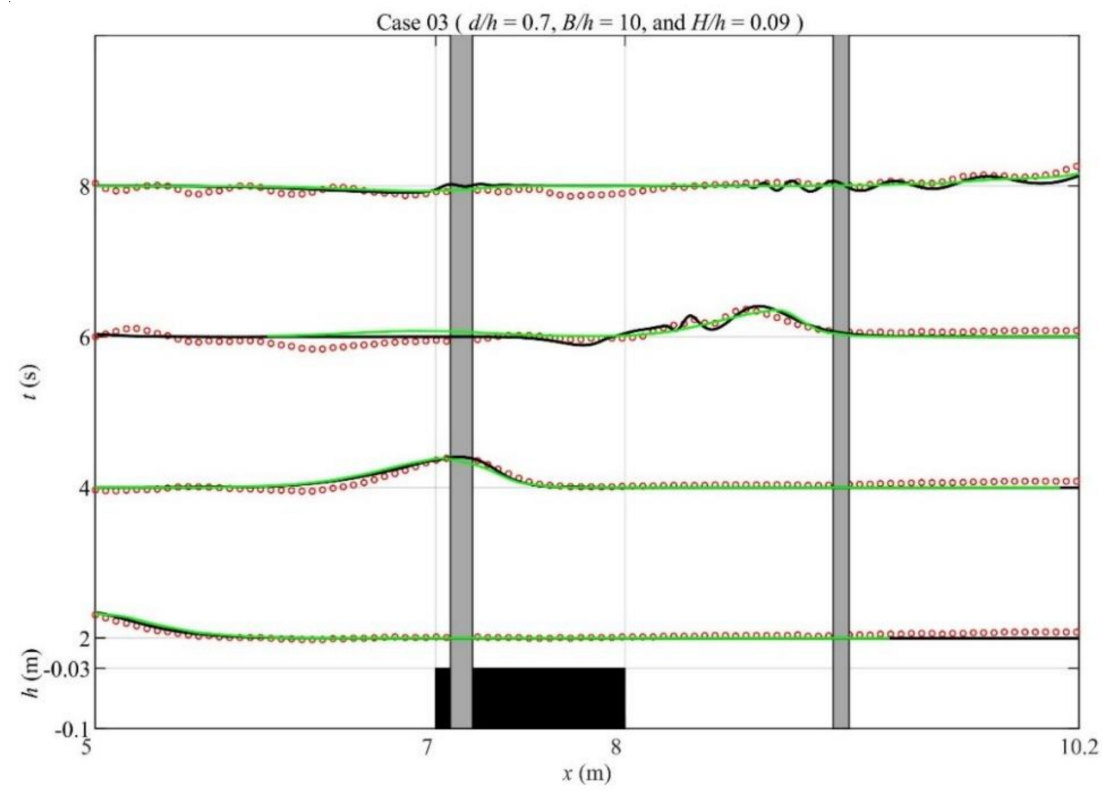

(b)

Figure 5. Snapshots of the wave profiles at $t=2,4,6$, and $8 \mathrm{~s}$ (from bottom to top): (a) Case 01, $d / h$ of 0.5 and (b) Case $03, d / h$ of 0.7 (circles denote experimental data; black lines denote FD results; grey lines denote FE results).

A study of solitary waves propagating over a submerged step with two shallow water depth ratios (i.e., $d / h$ values of 0.5 and 0.7 ) and various step width ratios ranging from 1 to 50 (i.e., $B / h$ values of $1-50$ ) was performed experimentally and numerically. Figure $6 a$ shows comparisons of the reflection coefficients with step heights for the experimental data (red squares), FD model results (black squares), and FE model results (green squares) with an $H / h$ of 0.09 and $B / h$ of 10 . The triangles in Figure 6 represent the value of the reflection coefficient with an $H / h$ of 0.09 and $B / h$ of 20 . In general, the reflection coefficient $(R)$ increases with the step height-water depth ratio $(d / h)$. It is noticeable that the step width height ( $d / h$ of 0.7 ) could lead to a $25-30 \%$ larger reflection coefficient in comparison with the cases with a shorter step $(d / h$ of 0.5$)$. Overall, the experimental data agree well with the FD and FE model results.

Figure $6 \mathrm{~b}$ shows a comparison of the transmission coefficients with the step heights for the present experiment data (red squares), FD model results (black squares), and FE model results (green squares) with an $H / h$ of 0.09 and $B / h$ of 10 . The transmission coefficient was less affected by the submerged step height for short submerged steps; i.e., a $d / h<0.5$. The transmission coefficients were quite close between the experimental and model results. For tall submerged steps, however, the transmission coefficient decreased significantly as the submerged step height increased; i.e., a $d / h>0.7$. The discrepancy for the tall submerged steps was likely due to the effect of bottom friction and viscosity, which was not considered in the models.

Figure $6 \mathrm{c}$ shows a comparison of the relation of the dissipation coefficient with the step height ratio for the results of the present experimental and numerical study. The dissipation of the solitary wave results from energy redistribution to higher-frequency components as well as energy losses due to bottom friction and viscous effects. As expected, the dissipation of energy was not strongly affected by short steps (see small dissipation coefficients for a $d / h<0.5)$. By contrast, over a tall step $(a d / h>0.5)$ where the effects of nonlinearity and the step corner would be significant, the wave energy rapidly dissipated. Note that both FD and FE models without the consideration of bottom friction and viscous effects would give a smaller dissipation coefficient that can be simply attributed to wave energy redistribution. It is also noted that the experimental data (red squares and triangles) and FD model results (black square and triangles) were over 30\% and 85\% larger than 
those of Lin [18]. The possible reason for this difference may result from the working depth of $0.1 \mathrm{~m}$ used in the present study, which is much smaller than the depth of $1.0 \mathrm{~m}$ used by Lin [18].
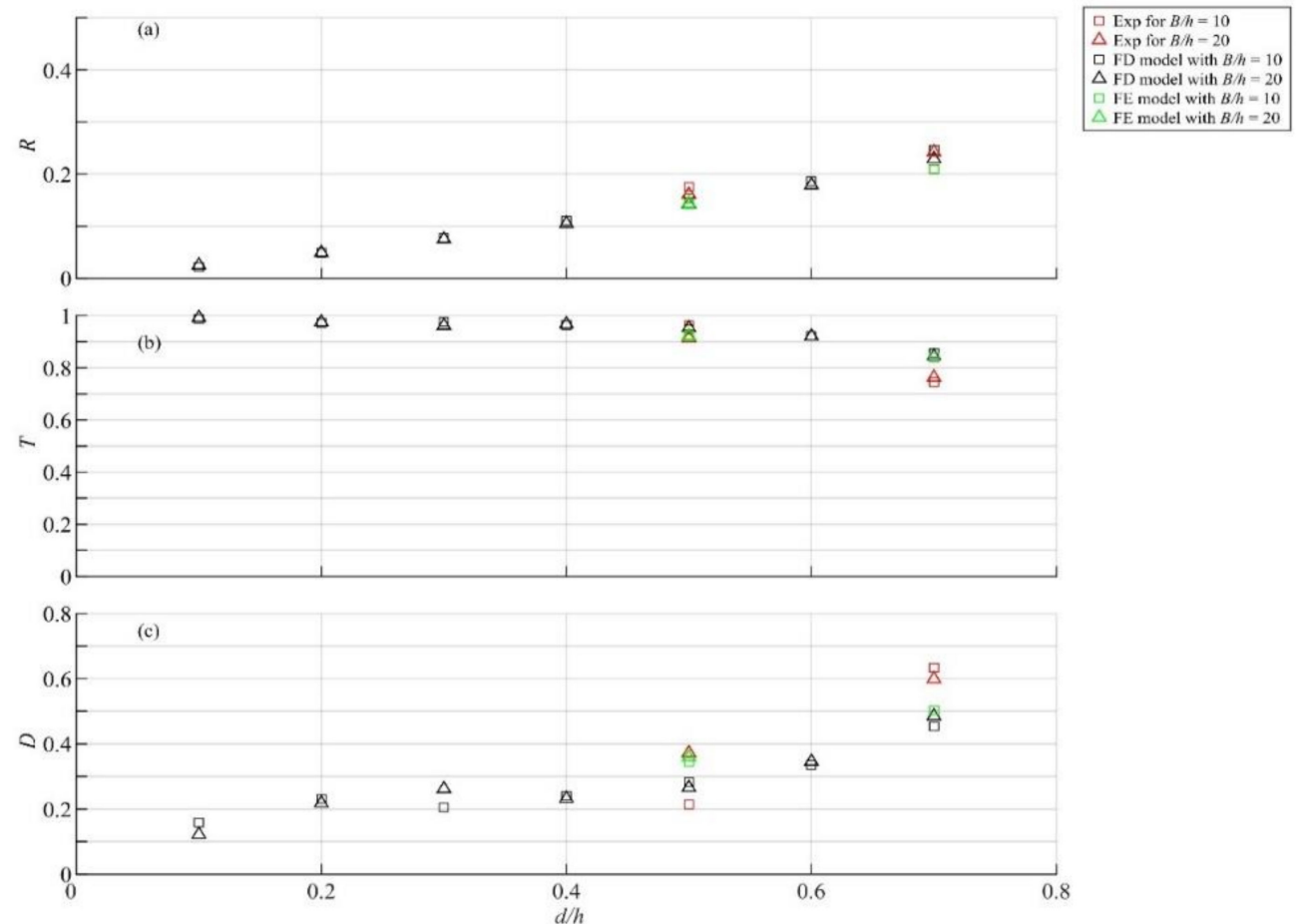

Figure 6. Relation of (a) reflection (b) transmission and (c) dissipation coefficient with step height for the solitary wave over a submerged step with step widths $B / h=10$ and 20 (red squares denote experimental results with $B / h=10$ and red triangles denote experimental results with $B / h=20$; black squares denote FD model results with $B / h=10$ and black triangles denote FD model results with $B / h=20$; green squares denote FE model results with $B / h=10$ and green triangles denote FE model results with $B / h=20$, respectively).

\subsection{Effect of Submerged Step Width}

A propagating solitary wave with a wave height $H$ of $0.009 \mathrm{~m}$ over a step with a height $h$ of $0.5 \mathrm{~m}$ and step widths $B$ of 1.0,3.0, and $5.0 \mathrm{~m}$ in a channel with a still water depth $h$ of $0.1 \mathrm{~m}$ were conducted numerically to study the effect of the submerged step width on the free-surface evolution and wave transformation.

Figure 7 show the comparison of the wave profiles of the two model simulation results. The wave profile of the two models showed good agreement as the solitary wave approached the submerged step $(t=4 \mathrm{~s}$ in Figure $7 \mathrm{a})$. As the solitary wave propagated into the deep-water region in the lee side of the submerged step, secondary soliton-like waves can be seen to have been generated ( $t=12 \mathrm{~s}$ in Figure $7 \mathrm{~b})$. It is noticeable that the predictions of the FE model (green lines) could not properly reproduce the process of energy transition due to these processes being outside of the applicable range of the depth-integrated non-hydrostatic models $[46,55,57]$. 

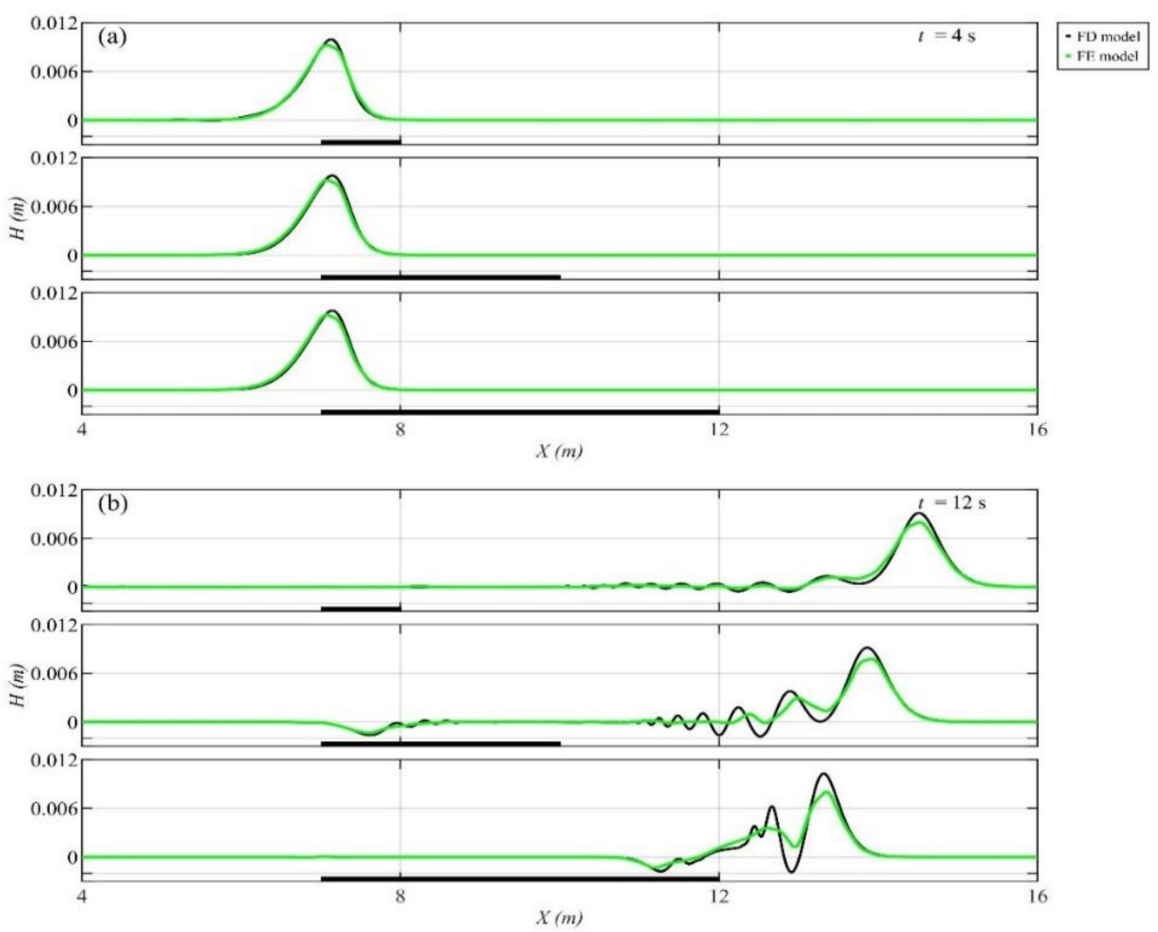

Figure 7. Comparison of the free surface at $t=(\mathbf{a}) 4 \mathrm{~s}$ and (b) $12 \mathrm{~s}$ for $B / h$ values of 10,30 , and 50 (black lines: FD model results; green lines: FE model results; the black thick line indicates the position of the submerged step).

Figure 8a depicts the relation of the reflection coefficient with different step widths $(B / h=0-50)$ for a propagating solitary wave with a wave height $H / h$ of 0.09 over a submerged step with height ratios $d / h$ of 0.5 and 0.7 . The reflection coefficient approached a constant (black squares) as the step width increased for steps with a $d / h$ of both 0.5 and 0.7. The reflection coefficient was found to be insensitive for submerged steps with a large width-i.e., a $B / h>10$-for steps with a $d / h$ of both 0.5 and 0.7 . In general, the present results are consistent with the early numerical works of Lin [18]. The prediction of the FD model and experimental data are consistent with early experimental results [27]. However, the value of the reflection coefficient of the present study is smaller than the value of Lin [18]. This discrepancy might be attributed to the linear wave assumption of Equation (1), which may be invalid here, especially for tall submerged steps (a $d / h>0.5)$.

Figure $8 \mathrm{~b}$ shows the comparisons between the FE model results (green squares), FD model results (black squares), and experimental data (red squares) under an $H / h$ of 0.09 , $B / h$ of $1-50$, and $d / h$ of 0.5 and 0.7 . Steps with a small height (d/h of 0.5$)$ resulted in a $45 \%$ larger transmission coefficient than tall steps ( $d / h$ of 0.7$)$. In comparison with Lin [18], the transmission coefficients obtained by the present FD model were in good agreement for the step with a $d / h$ of 0.5 . However, the transmission coefficients were found to be influenced by the steps with a $\mathrm{d} / \mathrm{h}$ of 0.7 . This observation might be due to waves breaking above the submerged step-the breaking process can lead to strong turbulence, large energy dissipation, and a smaller wave height, which were not considered in the present FD model. Figure $8 \mathrm{c}$ compares the dissipation coefficient with the submerged step width ( $B / h$ of $0-50)$ for an $H / h$ of 0.09 . Similarly, the energy dissipation did not increase with step width, particularly for a $d / h$ of 0.5 . However, for steps with a $d / h$ of 0.7 , the prediction of the dissipation coefficient of the FD model was smaller than that of Lin [18]. The reason for such a difference is the same; i.e., waves breaking above the submerged step, which leads to rapid energy loss (e.g., $60 \%$ ). 

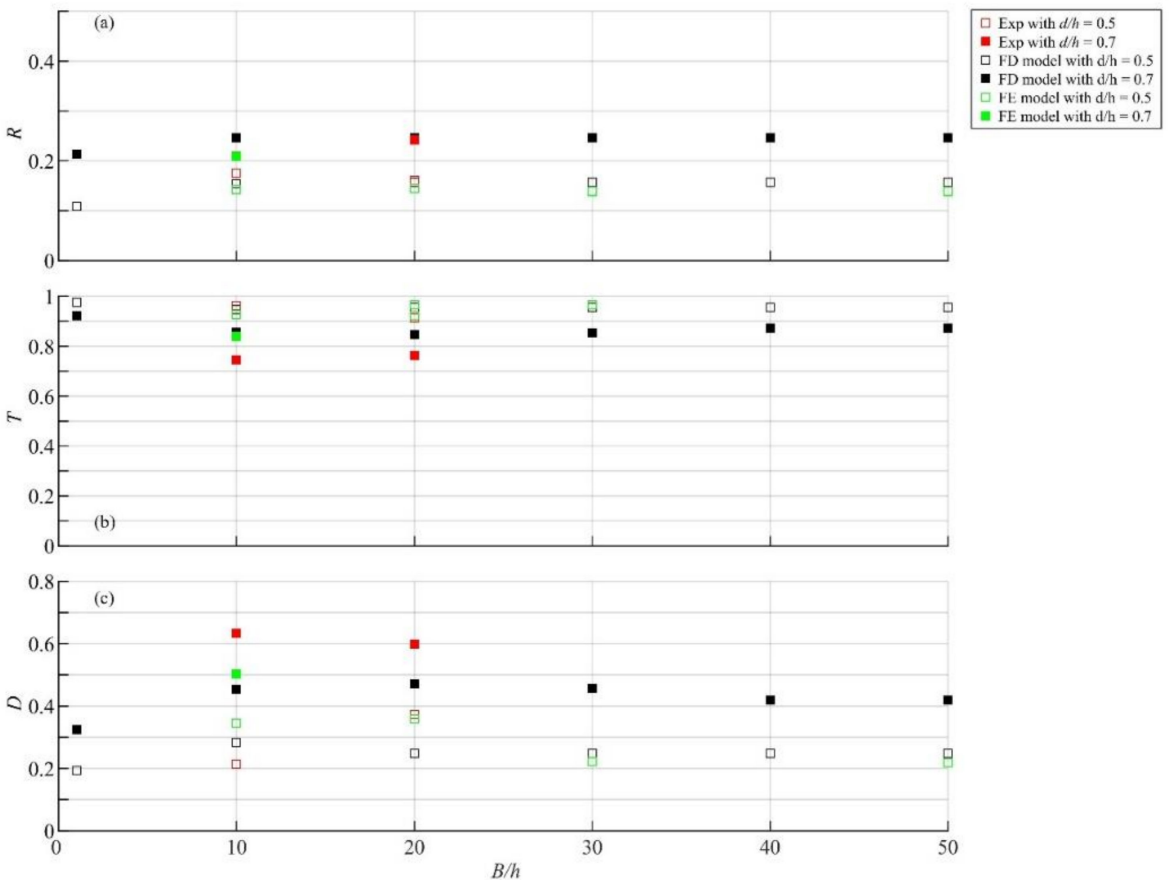

Figure 8. Relation of (a) reflection (b) transmission and (c) dissipation coefficient with the step width ratio $(B / h)$ for the solitary wave over a submerged step with step heights $d / h$ of 0.5 and 0.7 (red and filled squares denote experimental results with a $d / h$ of 0.5 and 0.7 ; black and filled squares represent FD model results with a $d / h$ of 0.5 and 0.7 ; green and filled squares denote FE model results with a $d / h$ of 0.5 and 0.7 , respectively).

\subsection{Effect of Solitary Wave Height}

Simulations of a solitary wave with wave heights $H$ of 0.009 and $0.0133 \mathrm{~m}$ propagating over a submerged step with a $d$ of $0.05 \mathrm{~m}, B$ of $1.0 \mathrm{~m}$ and $h$ of $0.1 \mathrm{~m}$ were performed to study the effect of solitary wave height, which is associated with nonlinearities and generation of high numbers of harmonics, on the wave evolution and transformation. Figure 9 shows the comparison between the results of the two models. Table 2 shows the summary of computed coefficients for the reflected $(R)$ and transmitted $(T)$ waves, and the dissipation $(D)$. Both FE and FD models presented adequate agreement in their simulations with experimental data with different initial wave heights ( $H / h$ values of 0.09 and 0.133$)$. The wave evolution and transformation of the larger initial wave height (Case 02) is more noticeable than with a smaller initial wave height (Case 01). The case with the higher initial wave height (Case 02) exhibited more energy transition than the case with the smaller initial wave height (Case 01) when the solitary wave propagated into the deep water of the lee side of the submerged step $(t>6 \mathrm{~s})$.

Table 2. Summary of computed coefficients for the reflected $(R)$ and transmitted $(T)$ waves, and the dissipation $(D)$.

\begin{tabular}{ccccccccccc}
\hline Case No. & $\boldsymbol{h} / \boldsymbol{d}$ & $\mathbf{R} \_$EXP & R_FD & R_FE & T_EXP & T_FD & T_FE & D_EXP & D_FD & D_FE \\
\hline Case 01 & 0.5 & 0.175 & 0.154 & 0.142 & 0.961 & 0.946 & 0.928 & 0.214 & 0.284 & 0.345 \\
Case 02 & 0.5 & 0.161 & 0.142 & 0.132 & 0.914 & 0.953 & 0.900 & 0.372 & 0.266 & 0.415 \\
Case 03 & 0.7 & 0.210 & 0.247 & 0.209 & 0.745 & 0.856 & 0.839 & 0.633 & 0.454 & 0.502 \\
Case 04 & 0.5 & 0.163 & 0.157 & 0.144 & 0.917 & 0.956 & 0.922 & 0.365 & 0.247 & 0.359 \\
Case 05 & 0.7 & 0.255 & 0.247 & 0.228 & 0.714 & 0.846 & 0.842 & 0.652 & 0.472 & 0.489 \\
Case 06 & 0.7 & 0.229 & 0.192 & 0.215 & 0.795 & 0.850 & 0.861 & 0.562 & 0.490 & 0.461 \\
Case 07 & 0.5 & NA & 0.157 & 0.139 & NA & 0.956 & 0.965 & NA & 0.247 & 0.222 \\
Case 08 & 0.5 & NA & 0.157 & 0.139 & NA & 0.956 & 0.966 & NA & 0.247 & 0.218 \\
\hline \multicolumn{7}{c}{ EXP experimental results, FD finite difference model results, FE finite element model results, NA available. }
\end{tabular}

EXP experimental results, ${ }^{\mathrm{FD}}$ finite difference model results, ${ }^{\mathrm{FE}}$ finite element model results, ${ }^{\mathrm{NA}}$ available. 


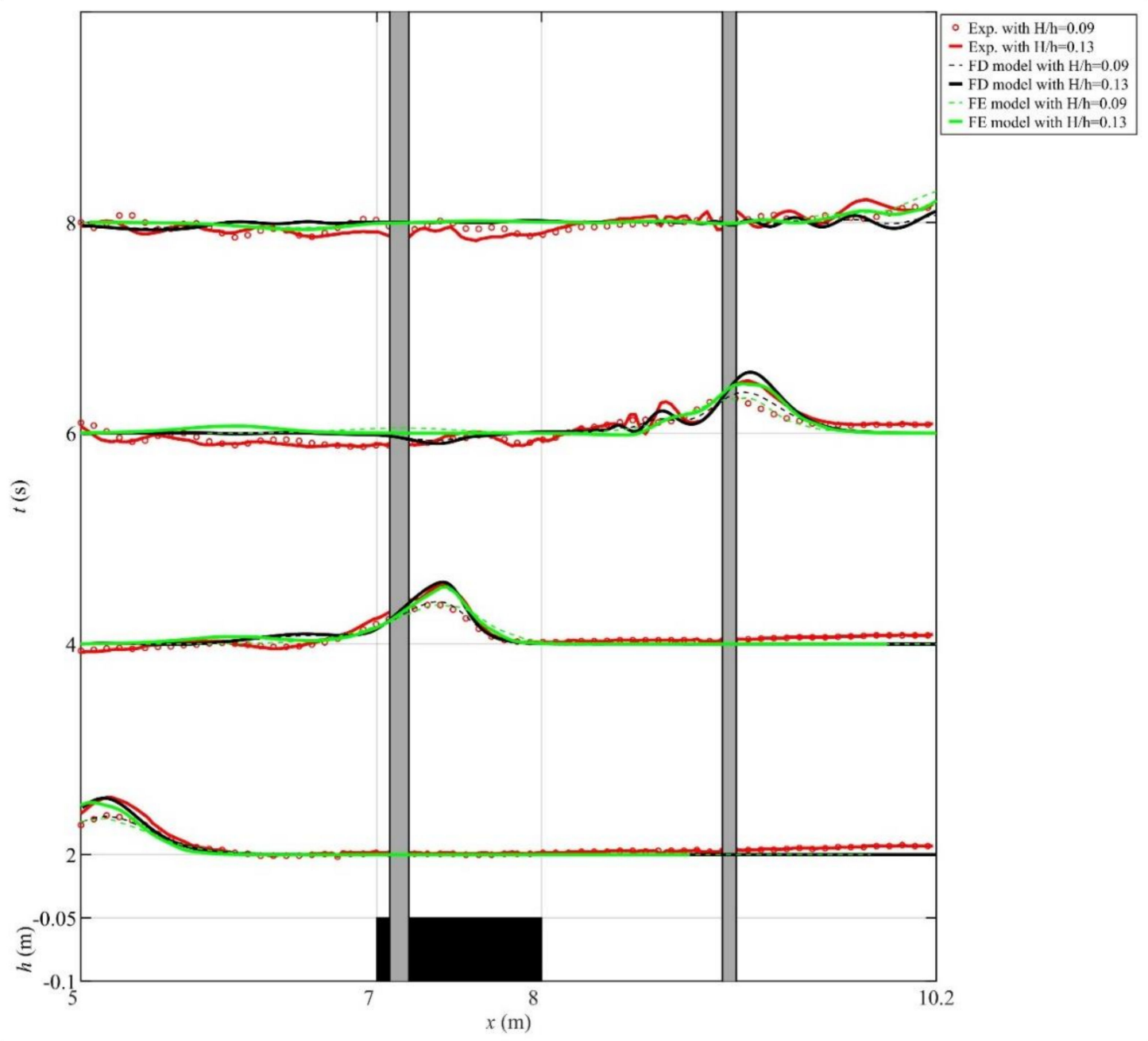

Figure 9. Snapshots of the wave profiles from bottom to top at $t=2,4,6$, and $8 \mathrm{~s}$ (red circles and dashed lines denote $H / h$ values of 0.09 and 0.13 for the experimental data; black dashed and solid lines denote $H / h$ values of 0.09 and 0.13 for the FD model; grey dashed and solid lines denote $H / h$ values of 0.09 and 0.13 for the FE model).

Energy dissipation is important for the protection and the design of coastal structures. To better depict the energy dissipation of a solitary wave, we proposed a set of combined parameters including the ratio of submergence height to water depth $(d / h)$, step width ratio $(B / h)$, and incident condition $(H / h)$ :

$$
D=A(d / h)^{p}(H / h)^{q}(B / h)^{r} .
$$

Figure 10 shows the multivariate regression results for the numerical experiments data with the powers $p=3.0, q=0.5$, and $r=0.1$, and an optimal correlation coefficient $C C=0.94:$

$$
D=1.667(d / h)^{3}(H / h)^{0.5}(B / h)^{0.1}
$$

Equation (8) indicates that $D$ is mostly influenced by the submergence ratio $(d / h)$ with an exponent of 3 and a square root of the incident condition $(H / h)$, and that it is barely influenced by the step width ratio $(B / h)$. Equation (8) serves as a reference for designing effective submerged breakwaters when in-situ environmental or numerical factors and marine meteorology data are available. A suitable value for the relative submerged height $d / h$ (the most significant parameter) can be chosen to yield a greater energy dissipation (D> $40 \%)$. 


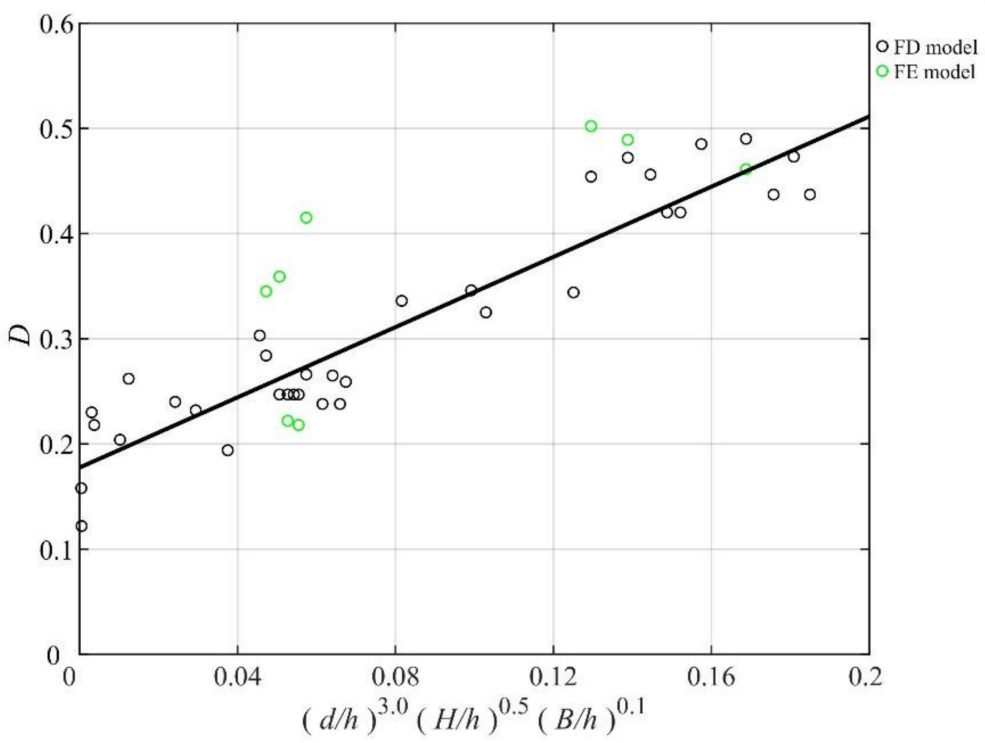

Figure 10. A parameter study of the relation of the dissipation coefficient $D$ with the combined parameters of $d / h, B / h$, and $H / h$ (the black line denotes the optimal regression; black and green circles denote FD and FE model results, respectively).

\section{Conclusions}

A series of solitary waves propagating over a submerged step was studied experimentally and numerically. A flow visualization measurement system and an image-connection technique $[32,33]$ were used in the experiment to record and process the evolution of the free surface and wave transformation. The experimental data were used to validate the one-layer finite-element and multi-layer finite-difference non-hydrostatic $\sigma$ model [47,52]. Various submerged step configurations and incident conditions of solitary waves were chosen to study their effects on reflection $(R)$, transmission $(T)$, and energy dissipation $(D)$. Based on the theory approximations, experimental data, and numerical results, the following conclusions can be drawn.

For simulation tools, two different models were employed. In general, the FE model can easily handle complicated geometries and boundary conditions. However, the FE is a $\mathrm{x}-\mathrm{y}$ 2D depth-averaged one-layer model. Since a small grid size $(d x)$ is used in simulations, the number of grids and degrees-of-freedom become large, even when one layer of the mesh is employed in the y-coordinate. As a result, the design and structure of the present FE model leads to a higher computational cost. For the model verification case, the CPU time of FE model is about 3-10 times that of that of the FD model. In contrast, the FD model is a high-order accurate multi-layer $\sigma$ model. The advantages, merits, and applications of the FD model can be found in [51,52]. Overall, the FD model outperforms the FE model in terms of computational accuracy and efficiency. Considering that the one-layer FE model is incapable of modeling dispersive short waves, the multi-layer modeling approach is suggested to improve the applicability scope of the FE in future study.

The computed coefficient of reflection and transmission shows good agreement with the experimental data for a shorter $d / h$ of 0.5 steps. It is also noticed that steps with a large depth (i.e., $d / h>0.7$ ) increase the reflection coefficient by $25 \sim 30 \%$ and decrease the transmission coefficient by $40 \sim 45 \%$ in both the numerical results and the experimental data. The reflection coefficient approaches a constant as the step width ratio increases and $B / h$ becomes $>10$. In general, the reflection coefficients of the study are consistent with earlier numerical work [18].

The value of the transmission coefficient for the experiments with steps with a $d / h$ of 0.5 was close to the prediction of FD model. The transmission coefficient of a step with a small height ( $d / h$ of 0.5$)$ increased by $45 \%$ compared with that of a tall step $(d / h$ of 0.7$)$. Generally, the numerical results of the width effect were also in reasonable agreement with 
the previous study by Lin [18]. Note that the breaking process considered in Lin [18] was not included in the present numerical models. As a result, the transmission coefficients were found to be influenced for cases with tall steps $(d / h$ of 0.7$)$. In other words, the discrepancy could be attributed to wave breaking, which leads to strong turbulence, large energy dissipation, and a smaller wave height above the submerged step.

Wave energy dissipation is important for the protection and design of coastal structures. The ratio of the submerged height $(d / h)$ has been found to be the most important parameter affecting the energy dissipation, as Equation (8) indicates. For a short step $(d / h<0.5)$, the dissipation of energy is not strongly affected by the step. In contrast, the wave energy over a tall step $(d / h>0.5)$ is rapidly dissipated. The dissipation coefficient of experimental (red squares and triangles) and numerical results (black squares and triangles) is $30 \%$ to $85 \%$ larger than that of an earlier study [18]. The possible reason for this discrepancy may result from the working depth of $0.1 \mathrm{~m}$ used in the present study, which is much smaller than the depth of $1.0 \mathrm{~m}$ used by Lin [18]. The effect of the step corners on wave dissipation cannot be ignored, especially for the short steps. The dissipation coefficient increases significantly as the ratio of submerged height $(d / h)$ becomes greater than 0.6 . For tall steps (i.e., $d / h$ of 0.7 ), the breaking process, which was not included in our numerical models, leads to strong and rapid energy loss, leading to a reduction of $60 \%$ in the study by Lin [18]. Moreover, the effect of the ratio of submerged widths $(B / h)$ on the dissipation becomes insignificant as the ratio grows larger than 10 .

Author Contributions: Conceptualization, W.-T.C., C.-C.Y. and S.-J.L.; experiment, W.-T.C. and C.-L.T.; numerical study, C.-C.Y. and S.-J.L.; formal analysis, W.-T.C., C.-C.Y. and C.-L.T.; writingoriginal draft preparation, W.-T.C. and C.-C.Y.; writing-review and editing, W.-T.C. and S.-J.L.; visualization, W.-T.C. All authors have read and agreed to the published version of the manuscript.

Funding: This research was funded by Ministry of Science and Technology, Taiwan, under grant number NSC99-2221-E-002-221-MY3, 107-2221-E-019-010-MY3 and 108-2218-E-019-001-MY2, and MOST 109-2221-E-019-043.

Institutional Review Board Statement: Not applicable.

Informed Consent Statement: Not applicable.

Data Availability Statement: The date presented in this study are available on request from the corresponding author (it is mandatory to cite the present paper when the data are used).

Acknowledgments: This study was provided by the Ministry of Science and Technology (MOST) and Ministry of Education (MoE), Taiwan.

Conflicts of Interest: The authors declare no conflict of interest.

\section{References}

1. Mimura, N.; Yasuhara, K.; Kawagoe, S.; Yokoki, H.; Kazama, S. Damage from the great east Japan earthquake and tsunami-A quick report. Mitig. Adapt. Strateg. Glob. Chang. 2011, 16, 803-818. [CrossRef]

2. Strusi'nska-Correia, A. Tsunami mitigation in Japan after 2011 Tohoku tsunami. Int. J. Disaster Risk Reduct. 2017, 22, 397-411. [CrossRef]

3. Ware, M.; Long, J.W.; Fuentes, M.M.P.B. Using wave runup modeling to inform coastal species management: An example application for sea turtle nest relocation. Ocean Coast. Manag. 2019, 173, 17-25. [CrossRef]

4. Wu, Y.T.; Hsiao, S.C. Propagation of solitary waves over a submerged slotted barrier. J. Mar. Sci. Eng. 2020, 8, 419. [CrossRef]

5. Goring, D.G. Tsunamis_The Propation of Long Waves onto a Shelf; California Institute of Technology: Pasadena, CA, USA, 1978.

6. Synolakis, C.E. The runup of solitary waves. J. Fluid Mech. 1987, 185, 523-545. [CrossRef]

7. Yeh, H.; Liu, P.L.-F.; Briggs, M.; Synolakis, C.E. Propagation and amplification of tsunamis at coastal boundaries. Nature 1994, 372, 353-355. [CrossRef]

8. Synolakis, C.E.; Bernard, E.N. Tsunami science before and beyond boxing day 2004. Philos. Trans. R. Soc. A 2006, 364, 2231-2265. [CrossRef]

9. Synolakis, C.E.; Bernard, E.N.; Titov, V.V.; Kãnoglu, U.; González, F.I. Validation and verification of tsunami numerical models. Pure Appl. Geophys. 2008, 165, 2197-2228. [CrossRef]

10. Macayel, D.R.; Abbot, D.S.; Sergienko, O.V. Iceberg-Capsize tsunamigenesis. Ann. Glaciol. 2011, 52, 51-56. [CrossRef] 
11. Liu, P.L.F.; Synolakis, C.E.; Yeh, H. Report on the international workshop on long-wave run-up. J. Fluid Mech. 1991, $229,675-688$. [CrossRef]

12. Russell, J.S. Report on Waves, Proceedings of the 14th Meeting of the British Association for the Advancement of Science, York, UK, September 1844; British Association for the Advancement of Science: London, UK, 1845; pp. 311-390.

13. Mei, C.C.; Black, J.L. Scattering of surface waves by rectangular obstacles in waters of finite depth. J. Fluid Mech. 1969, 38, 499-511. [CrossRef]

14. Vaziri, N.; Chern, M.J.; Borthwick, A.G. A pseudo spectral $\sigma$-transformation model of solitary waves in a tank with uneven bed. Comput. Fluids 2011, 49, 197-202. [CrossRef]

15. Li, J.; Liu, H.; Gong, K.; Tan, S.K.; Shao, S. SPH modeling of solitary wave fissions over uneven tank bottoms. Coast. Eng. 2012, 60, 261-275. [CrossRef]

16. Papoutsellis, C.; Charalampopoulos, A.; Athanassoulis, G. Implementation of a fully nonlinear Hamiltonian coupled-mode theory, and application to solitary wave problems over bathymetry. Eur. J. Mech. B Fluids 2018, 72, 199-224. [CrossRef]

17. Losada, M.A.; Vidal, V.; Medina, R. Experimental study of the evolution of a solitary wave at an abrupt junction. J. Geophys. Res. 1989, 94, 14557. [CrossRef]

18. Lin, P. A numerical study of solitary wave interaction with rectangular obstacles. Coast Eng. 2004, 51, 35-51. [CrossRef]

19. Lu, J.; Yu, X. Numerical study of solitary wave fission over an underwater step. J. Hydrodynam. B 2008, 20, 398-402. [CrossRef]

20. Ji, Q.; Dong, S.; Luo, X.; Guedes, S.C. Wave transformation over submerged breakwaters by the constrained interpolation profile method. Ocean Eng. 2017, 136, 294-303. [CrossRef]

21. Wu, Y.T.; Hsiao, S.C. Propagation of solitary waves over double submerged barriers. Water 2017, 9, 917. [CrossRef]

22. Han, X.; Dong, S. Interaction of solitary wave with submerged breakwater by smoothed particle hydrodynamics. Ocean Eng. 2020, 216, 108108. [CrossRef]

23. Goring, D.G.; Raichlen, F.R. Propagation of long waves onto shelf. J. Waterw. Port Coast. Ocean Eng. 1992, 118, 43-61. [CrossRef]

24. World Bank; United Nations. Nature Hazards, Unnatural Disasters: The Economics of Effective Prevention; World Bank: Washington, DC, USA, 2010.

25. Ha, T.; Yoo, J.; Han, S.; Cho, Y.S. Numerical study on tsunami hazard mitigation using a submerged breakwater. Sci. World J. 2014, 1-11. [CrossRef]

26. Johnson, R.S. Some numerical solutions of variable-coefficient Korteweg-deVries equation (with application to solitary wave development on a shelf). J. Fluid Mech. 1972, 54, 81-91. [CrossRef]

27. Miles, J.W. On internal solitary waves. Tellus 1979, 31, 456-462. [CrossRef]

28. Kanoglu, U.; Synolakis, C.E. Long wave runup on piecewise linear topographies. J. Fluid Mech. 1998, 374, 1-28. [CrossRef]

29. Nakuolima, O.; Zahibo, N.; Pelenovsky, E.; Taipove, T.; Kurkin, A. Solitary wave dynamics in shallow water over periodic topography. Chaos 2005, 15, 037107. [CrossRef]

30. Pelinovsky, E.; Choi, B.H.; Talipova, T.; Woo, S.B.; Kim, D.C. Solitary wave transformation on the underwater step: Asymptotic theory and numerical experiments. Appl. Math. Comput. 2010, 217, 1704-1718. [CrossRef]

31. Seabra-Santos, F.J.; Renouard, D.; Temperville, A. Numerical and experimental study of the transformation of a solitary wave over a shelf or isolated obstacle. J. Fluid Mech. 1987, 176, 117-134. [CrossRef]

32. Li, F.C.; Ting, C.L. Separation of free and bound harmonics in waves. Coast. Eng. 2012, 67, 29-40. [CrossRef]

33. Ting, C.L.; Chao, W.T.; Young, C.C. Experimental investigation of nonlinear regular wave transformation over a submerged step: Harmonic generation and wave height modulation. Coast. Eng. 2016, 117, 19-31. [CrossRef]

34. Wu, Y.T.; Hsiao, S.C.; Huang, Z.C.; Hwang, K.S. Propagation of solitary over a bottom-mounted barrier. Coast. Eng. 2012, 62, 31-47. [CrossRef]

35. Lin, C.; Chang, S.C.; Ho, T.C.; Chang, K.A. Laboratory observation of solitary wave propagation over a submerged rectangular dike. J. Eng. Mech. 2006, 132, 545-554. [CrossRef]

36. Lin, C.; Ho, T.C.; Dey, S. Experimental study on the characteristics of steady horseshoe vortex system near the junction of rectangular cylinder and base plate. J. Eng. Mech. 2008, 134, 184-197. [CrossRef]

37. Wu, Y.T.; Hsiao, S.C. Turbulence induced by a solitary wave propagating over a submerged object using particle image velocimetry. J. Coast. Res. 2013, 65, 416-421. [CrossRef]

38. Wu, Y.T.; Hsiao, S.C. Propagation of solitary waves over a submerged permeable breakwater. Coast. Eng. 2013, 81, 1-18. [CrossRef]

39. Liu, P.L.F.; Al-Banaa, K.; Cowen, E.A. Water wave induced boundary layer flows above a ripple bed. In PIV and Water Waves; World Scientific: Singapore, 2008; pp. 81-117.

40. Athanassoulis, G.; Mavroeidis, C.; Koutsogiannakis, P.; Papoutsellis, C. A numerical study of the run-up and the force exerted on a vertical wall by a solitary wave propagating over two tandem trenches. J. Ocean Eng. Mar. Energy 2019, 5, 311-331. [CrossRef]

41. Huang, C.J.; Chen, C.H.; Chang, H.H. Propagation of water waves over permeable rippled beds. Ocean Eng. 2011, 38, 579-591. [CrossRef]

42. Shen, L.; Chan, E.S. Application of a combined ib-vof model to wave-structure interaction. Appl. Ocean Res. 2010, 32, 40-48. [CrossRef]

43. Lin, P.; Liu, P.L.F. A numerical study of breaking waves in the surf zone. J. Fluid Mech. 1998, 359, 239-264. [CrossRef]

44. Lin, P.; Liu, P.L.F. Turbulence transport, vorticity dynamics, and solute mixing under plunging breaking waves in surf zone. J. Geophys. Res. 1998, 103, 15677-15694. [CrossRef] 
45. Yeganeh-Bakhtiary, A.; Hajivalie, F.; Hashemi-Javan, A. Steady streaming and flow turbulence in front of vertical breakwater with wave overtopping. Appl. Ocean Res. 2010, 32, 91-102. [CrossRef]

46. Liang, S.J.; Young, C.C.; Dai, C.; Wu, N.J.; Hsu, T.W. Simulation of ocean circulation of Dongsha water using non-hydrostatic shallow-water model. Water 2020, 12, 2832. [CrossRef]

47. Young, C.C.; Wu, C.H.; Kuo, J.T.; Liu, W.C. A high-order $\sigma$-coordinate no-hydrostatic model for nonlinear surface waves. Ocean Eng. 2007, 34, 1357-1370. [CrossRef]

48. Guizien, K.; Barthelemy, E. Accuracy of solitary wave generation by a piston wave maker. J. Hydraul. Res. 2002, 40, 321-331.

49. Young, C.C.; Wu, C.H.; Liu, W.C.; Kuo, J.T. A high-order non-hydrostatic $\sigma$ model for simulating non-linear refraction-diffraction of water waves. Coast. Eng. 2009, 56, 919-930. [CrossRef]

50. Ma, G.; Shi, F.; Kirby, J.T. Shock-Capturing non-hydrostatic model for fully dispersive surface wave processes. Ocean Model. 2012, 43, 22-35. [CrossRef]

51. Young, C.C.; Wu, C.H. Nonhydrostatic modeling of nonlinear deep-water wave groups. J. Eng. Mech. 2010, 136, 155-167. [CrossRef]

52. Young, C.C.; Chao, W.T.; Ting, C.L. Applicable sloping range and bottom smoothing treatment for $\sigma$-based modeling of wave propagation over rapidly varying topography. Ocean Eng. 2016, 125, 261-271. [CrossRef]

53. Young, C.C.; Wu, C.H.; Hsu, T.W. The role of non-hydrostatic effects in nonlinear dispersive wave modeling. Water 2020, $12,3513$. [CrossRef]

54. Stelling, G.S.; Van-Kester, J.A.T.M. On the approximation of horizontal gradients in sigma co-ordinates for bathymetry with steep bottom slopes. Int. J. Numer. Methods Fluids 1994, 18, 915-935. [CrossRef]

55. Yuan, H.; Wu, C.H. A two dimensional vertical non-hydrostatic s-model with an implicit method for free-surface flows. Int. J. Numer. Methods Fluids 2004, 44, 811-835. [CrossRef]

56. Mitotakis, D.; Synolakis, C.; McGuinness, M. A modified Galerkin/finite element method for the numerical solution of the Serre-Green-Naghdi system. Int. J. Numer. Methods Fluids 2016, 83, 755-778. [CrossRef]

57. Stelling, G.S.; Zijlema, M. An accurate and efficient finite-difference algorithm for non-hydrostatic free-surface flow with application to wave propagation. Int. J. Numer. Methods Fluids 2003, 43, 1-23. [CrossRef]

58. Yuan, H.; Wu, C.H. Fully nonhydrostatic modeling of surface waves. J. Eng. Mech. 2006, 132, 447-456. [CrossRef]

59. Liang, S.J.; Tang, J.H.; Wu, M.S. Solution of shallow-water equations using least-squares finite-element method. Acta Mech. Sin. 2008, 24, 523-532. [CrossRef]

60. Liang, S.J.; Hsu, T.W. Least-Squares finite-element method for shallow-water equations with source terms. Acta Mech. Sin. 2009, 25, 597-610. [CrossRef]

61. Casulli, V. Semi-Implicit finite difference methods for two-dimensional shallow water equations. J. Comput. Phys. 1990, 86, 56-74. [CrossRef]

62. Casulli, V. A semi-implicit finite difference method for non-hydrostatic, free surface flows. Int. J. Numer. Methods Fluids 1999, 30, 425-440. [CrossRef]

63. Keller, H.B. A new difference scheme for parabolic problems. In Numerical Solutions of Differential Equations-II, Proceedings of the Second Symposium on the Numerical Solution of Partial Differential Equations, College Park, MD, USA, 11-15 May 1970; Hubbard, B., Ed.; Academic Press: New York, NY, USA, 1971; pp. 327-350.

64. Casulli, V.; Stalelling, G.S. Numerical simulation of 3D quasi-hydrostatic, free surface flows. J. Hydraul. Eng. 1998, 124, 678-686. [CrossRef]

65. Wei, P.; Jia, Y. A depth-integrated non-hydrostatic finite element model wave propagation. Int. J. Numer. Methods Fluids 2013, 73, 976-1000. [CrossRef]

66. Walters, R.A. A semi-implicit finite element model for non-hydrostatic (dispersive) surface waves. Int. J. Numer. Methods Fluids 2005, 49, 721-737. [CrossRef]

67. Yamazaki, Y.; Kowalik, Z.; Cheung, K.F. Depth-Integrated, non-hydrostatic model for wave breaking and run-up. Int. J. Numer. Methods Fluids 2008, 61, 473-497. [CrossRef] 